1

2

3

4

5

6

7

8

9

10

11

12

13

14

15

16

17

18

19

20

21

\section{PDZ and LIM domain protein 2 plays dual and context-dependent roles in breast cancer} development

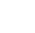

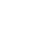

Josef Maryas $^{1,2}$, Jan Pribyl $^{3}$, Pavla Bouchalova $^{1}$, Petr Skladal $^{1,3}$ and Pavel Bouchal ${ }^{1}$ *

${ }^{1}$ Masaryk University, Faculty of Science, Department of Biochemistry, Brno, Czech Republic

${ }^{2}$ Masaryk Memorial Cancer Institute, Regional Centre for Applied Molecular Oncology, Brno, Czech 8 Republic

${ }^{3}$ Masaryk University, Central European Institute for Technology, Brno, Czech Republic

*Corresponding author:

Pavel Bouchal, Ph.D.

Masaryk University

Faculty of Science

Department of Biochemistry

Kamenice 5

62500 Brno

Czech Republic

Phone: +420-549493251

E-mail: bouchal@chemi.muni.cz 
PDZ and LIM domain protein 2 (PDLIM2) is a cytoskeletal and nuclear effector that regulates the activity of several transcription factors (e.g., NF-кB, STAT), and its deregulation has been associated with oncogenesis. Our recent study identified PDLIM2 as a protein associated with the lymph node metastasis of low grade luminal A breast cancer tissues. Here, we aim to understand this association at the molecular and cellular levels.

Methods

To investigate the link between PDLIM2 and epithelial-to-mesenchymal transition (EMT), stably transduced MCF7-PDLIM2 cells, and MCF7 or MCF10A cells with PDLIM2 protein levels modified using siRNA or PDLIM2 gene carrying plasmid, were used. Additionally, MCF7 and MCF10A cells were exposed to hypoxic conditions and TGF $\beta 1$ treatment. EMT was monitored using immunoblotting of EMT markers and atomic force microscopy (AFM). The role of PDLIM2 in cell migration and/or invasion was investigated using Transwell assay and xCELLigence system.

First, we observe a positive effect of PDLIM2 overexpression on EMT in MCF7 cells, a model of luminal A tumors, using EMT markers and AFM. On the other hand, PDLIM2 helps to maintain the epithelial phenotype in MCF10A cells, a model of normal breast epithelial cells. Second, we find that exposure of the MCF7 cells to hypoxic conditions increases levels of PDLIM2 and carbonic anhydrase-9 (CA-9), a marker of the response to hypoxia. However, none of these effects are observed

42 in the MCF10A cells. Third, PDLIM2 overexpression promotes migration, invasion, and proliferation and decreases adhesion of the MCF7 cells, but an opposite effect is observed in the MCF10A cells. 
44 Conclusions

45 Our data indicate that PDLIM2 plays a dual role: (i) as an EMT-supporting and hypoxia-responding

46 oncoprotein in luminal breast cancer cells, and (ii) as an epithelial phenotype-maintaining tumor

47 suppressor in normal epithelial breast cells.

\section{$48 \quad$ KEYWORDS}

49 PDLIM2; EMT; metastasis; luminal A breast cancer; hypoxia; MCF10A cells 


\section{BACKGROUNDS}

52

Breast cancer is the most common form of cancer and the second cause of death of women worldwide.

Distant metastases represent the main reason for patient mortality [1, 2]. For risk group discrimination and determination of the metastatic potential of breast tumors in clinical practice, both traditional and molecular prognostic markers have been used. However, currently available markers are not sufficient for precise determination of metastatic potential $[3,4]$. This insufficiency is well demonstrated by the low grade luminal A breast cancer subtype, whose general prognosis is favorable; nevertheless, approximately one-third of these tumors exhibit early lymph node metastases in disagreement with the initial prognosis. The molecular mechanism responsible for this lapse is unknown [3]. To improve understanding, we identified a panel of proteins associated with lymph node metastasis in low grade luminal A breast cancer using combined proteomics and transcriptomics [5]. PDZ and LIM domain protein 2 (PDLIM2), also known as Mystique or SLIM, was one of the key proteins in this panel, and its mRNA and protein levels were upregulated in a set of 24 lymph node-positive luminal A grade 1 tumors compared to their 24 lymph node-negative counterparts, specifically in this subtype. Additionally, the PDLIM2 protein level was higher in grade 1 vs. grade 3 tumors and in HER2 vs. HER $2^{+}$breast cancer in a set of 96 breast tumors in total, indicating its connection with the luminal A subtype, low tumor grade, and high metastatic potential.

PDLIM2 is a member of the actinin-associated LIM protein (ALP) family, which contains a single Nterminal PDZ domain and C-terminal LIM domains [6]. All members of the ALP family are known to interact with the actin cytoskeleton [7] and play essential roles in its organization, cell differentiation, organ development, and neural signalization and have been associated with oncogenesis in general [8]. PDLIM2 acts as an E3 ubiquitin ligase and as such regulates the stability of NF- $\mathrm{BB}$ and other transcription factors in hematopoietic and epithelial cells. Its deregulation has been associated with several malignancies [7, 9-10]. The PDLIM2 gene is localized on chromosome $8 \mathrm{p} 21$, a region frequently disrupted in various cancers [10-11], and its expression has been previously connected with both tumor suppression and oncogenesis [10]. PDLIM2 expression is epigenetically suppressed by promoter hypermethylation in different cancers [10], and its re-expression is able to inhibit 
tumorigenicity and induce tumor cell death both in vitro and in vivo [12]. It was first identified in corneal epithelial cells [6] and in fibroblasts transformed by overexpression of the insulin-like growth factor 1 receptor (IGF-1R), T-lymphocytes, macrophages, dendritic cells and epithelial cancer cells [67, 9-11]. On the other hand, PDLIM2 is highly expressed in invasive cancer cells, and its expression is associated with tumor progression and metastasis $[5,9]$.

Controversial literature results on the role of PDLIM2 in cancer development led us to assumptions about its dual and context-dependent role [13]. To test this hypothesis, we performed a series of in vitro experiments at the molecular and cellular levels using MCF7 breast cancer cells and MCF10A immortalized normal epithelial breast cells. Comparison of migration and invasion abilities as well as association with epithelial-to-mesenchymal transition (EMT) and hypoxia of different cell lines with modulated levels of PDLIM2 confirmed our hypothesis regarding the dual and context-dependent roles of PDLIM2 in breast cancer. Based on our data, we postulated a precise hypothesis about the cyclic changes of PDLIM2 protein levels during the oncogenesis of breast cancer, which also explains the inconsistency among previously published studies.

\section{MATERIALS AND METHODS}

\section{Reagents and antibodies}

Pyruvate, bromophenol blue, glycerol, mercaptoethanol, acrylamide, TEMED, APS, Tween 20, SDS, Tris $\mathrm{HCl}$, HEPES, PEI, TGF $\beta 1$, luminol, coumaric acid, resazurin, insulin, $\mathrm{CH}_{3} \mathrm{COONa}$, $\mathrm{NaBO}_{3} .4 \mathrm{H}_{2} \mathrm{O}, \mathrm{NaCl}, \mathrm{KCl}, \mathrm{Na}_{2} \mathrm{HPO}_{4} .12 \mathrm{H}_{2} \mathrm{O}, \mathrm{KH}_{2} \mathrm{PO}_{4}, \mathrm{MgCl}_{2}$, and $\mathrm{NaH}_{2} \mathrm{PO}_{4}$ were purchased from Sigma-Aldrich. Streptomycin/penicillin, trypsin and EGTA were purchased from Invitrogen. Fetal bovine serum and horse serum were purchased from Biochrom AG, GoldView ${ }^{\mathrm{TM}}$ was obtained from Viswagen, EDTA from Serva, EGF from Millipore, Calcein AM from Biotium, crystal violet from Merck, hydrocortisone from VUAB Pharma, and formaldehyde from Penta. Mouse anti-E-cadherin (diluted 1:100) antibody $(\mathrm{Ab})$ and anti-vimentin $\mathrm{Ab}(1: 1000)$ were purchased from DakoCytomation, mouse anti-p65 Ab (1:500) was purchased from Santa Cruz Biotechnology, mouse anti-N-cadherin Ab was purchased from Invitrogen, mouse anti-actin Ab (1:250) was purchased from Sigma Aldrich and 
mouse anti-PDLIM2 Ab (1:250) was purchased from Origene. Rabbit anti-FAK Abs (1:500), anti- $\beta$ catenin $\mathrm{Ab}$ (1:500) and anti-p-p53 (phosphorylated on S20) Ab (1:500) were purchased from Cell Signaling. Mouse anti-CA9 Ab (M75, diluted 1:3), anti-KRT18 Ab (DC10, 1:10), anti-p53 (DO-1, 1:10) and anti-PCNA $\mathrm{Ab}(\mathrm{PC} 10,1: 10)$ were prepared in-house. Horseradish peroxidase-conjugated RAMPx and SWARPx Abs (both DakoCytomation, dilution 1:1000) were used as secondary Abs. All antibodies were diluted in PBS with $0.1 \%$ Tween 20 containing 5\% nonfat milk.

\section{Cell lines, cell culture and cell counting}

The human ER-positive breast cancer cell line MCF7 and ER-negative breast cancer cell lines MDAMB-231 and BT-549 were maintained in DMEM supplemented with 10\% FBS, $1.25 \mathrm{mM}$ pyruvate, $0.172 \mathrm{mM}$ streptomycin and $100 \mathrm{U} / \mathrm{ml}$ penicillin. The human nontumorigenic breast epithelial cell line MCF10A was cultivated in DMEM/F12 supplemented with $5 \%$ horse serum, $1.25 \mathrm{mM}$ pyruvate, $0.172 \mathrm{mM}$ streptomycin, $100 \mathrm{U} / \mathrm{ml}$ penicillin, $20 \mathrm{ng} / \mathrm{ml}$ EGF, $0.5 \mathrm{mg} / \mathrm{ml}$ hydrocortisone and $10 \mu \mathrm{g} / \mathrm{ml}$ insulin. All cell lines were purchased from the American Type Culture Collection (ATCC). The cells were counted using a CASY TT cell counting device (Roche, Mannheim, Germany) or Bürker chamber for adhesion, proliferation, migration and invasion experiments.

\section{Commercial plasmids and siRNAs}

For specific plasmid preparation, the pENTR221 "entry" vector and pcDNA3-GW-DEST "destination" vector were used (both from Invitrogen). Empty pcDNA3-GW-DEST served also as a CTRL plasmid in the experiments. On-Target plus SMART pool human PDLIM2 siRNA was used for PDLIM2 suppression (600 nM concentration, cat. no. L-005152-00). As a control, CTRL siRNA OnTarget plus Nontargeting pool control siRNA (cat. no. D-001810-10-20) was used also at a concentration of $600 \mathrm{nM}$ (both siRNAs from Dharmacon, Thermo Scientific). 
Total RNA was isolated from the BT-549, MDA-MB-231 and MCF7 cell lines using an RNeasy Mini

Kit 250 (Qiagen) according to the manufacturer's protocol. The isolated RNA was pooled, eluted into $50 \mu \mathrm{l}$ of RNase-free water, and stored at $-80{ }^{\circ} \mathrm{C}$. Complementary DNA (cDNA) was synthesized and amplified using a One Step RT PCR kit (Invitrogen) with PDLIM2-specific primers: forward 5'CGGCGCCGGGCTCCTCTC-3 ' and reverse 5'-CCCTGGCCCACCCCTCTCCTTCC-3'. The reaction mixture contained $1 \mathrm{M}$ betain, $1 \mathrm{x}$ Reaction Mix, $0.36 \mathrm{M}$ trehalose, $1 \mu$ of SuperScript ${ }^{\mathrm{TM}}$ III RT/Platinum Taq Hi Fi Enzyme Mix, $0.5 \mu \mathrm{g}$ of total RNA, and primers at a concentration $0.4 \mu \mathrm{M}$, and nuclease-free water was added to the final volume of $50 \mu$. The PCR program included two steps of cDNA synthesis $\left(50{ }^{\circ} \mathrm{C}\right.$ for $30 \mathrm{~min}$ and $80{ }^{\circ} \mathrm{C}$ for $\left.3 \mathrm{~min}\right)$, predenaturation at $95{ }^{\circ} \mathrm{C}$ for $30 \mathrm{~s}$, and 10 amplification cycles - each consisting of denaturation at $95^{\circ} \mathrm{C}$ for $5 \mathrm{~s}$, annealing at $55^{\circ} \mathrm{C}$ for $30 \mathrm{~s}$ and extension at $68{ }^{\circ} \mathrm{C}$ for $3 \mathrm{~min}$, followed by further extension at $68^{\circ} \mathrm{C}$ for $1 \mathrm{~min}$. The resulting product was purified using the standard protocol of the QIAquick PCR Purification Kit (Qiagen).

\section{Construction of the pcDNA3-PDLIM2-GW-DEST plasmid}

Gateway technology (Thermo Fisher Scientific) was used to construct the PDLIM2-carrying plasmid.

The cDNA fragment of PDLIM2 was amplified using PCR with Herculase II DNA polymerase, a pair of specific

primers,

PDLIM2

TEV

forward

$\left(5^{\prime}-\right.$

GGCTCTGAGAACCTGTACTTCCAGAGCATGGCGTTGACGGTGGATGTG-3', bearing a region coding the sequence recognized by TEV protease) and PDLIM2 GWs reverse (5'GTACAAGAAAGCTGGGTTTCAGGCCCGAGAGCTGAGG-3', bearing a stop codon), and a pair

universal

primers,

TEV

forward

(TEV

F: $\quad 5$ '-

GGGGCTGCTTTTTTGTACAAACTTGTCCGAGACTCTTGG-3') and ATTB2 reverse (ATTB2 R: 5'-GGGGCAGCTTTCTTGTACAAAGTGGGACATGTTCTTTCG-3'). The reaction mixture contained $1 \mathrm{M}$ betain, $20 \mu \mathrm{l}$ of cDNA, $1 \mathrm{x}$ reaction buffer, $1 \mathrm{mM}$ dNTP, $1 \mu 1$ of Herculase II, specific primers at $0.1 \mu \mathrm{M}$ and universal primers at $0.3 \mu \mathrm{M}$, and nuclease-free water was added to the final volume of $50 \mu \mathrm{l}$. The PCR program included predenaturation at $95{ }^{\circ} \mathrm{C}$ for $1 \mathrm{~min}$ and 30 amplification 
153 cycles - each consisting of denaturation at $95^{\circ} \mathrm{C}$ for $10 \mathrm{~s}$, annealing at $50{ }^{\circ} \mathrm{C}$ for $20 \mathrm{~s}$ and extension at

$15470{ }^{\circ} \mathrm{C}$ for $90 \mathrm{~s}$, followed by further extension at $70{ }^{\circ} \mathrm{C}$ for $5 \mathrm{~min}$. The final product was separated by

155 electrophoresis on a $1.5 \%$ GoldView $^{\mathrm{TM}}$ stained agarose gel and visualized under UV light by a CCD

156 camera. The target fragment was extracted by a QIAquick Gel Extraction Kit (Qiagen) according to

157 the manufacturer's protocol, and $150 \mathrm{ng}$ were used for the BP recombinant reaction with pDONR221

158 according to the Gateway technology manual (Thermo Fisher Scientific). Chemically competent

159 E. coli TOP10 (Life Technologies) cells were used for the preparation and amplification of resulting

160 entry vector (pENTR221-PDLIM2). The QIAprep Spin Miniprep Kit (Qiagen) was used for vector

161 purification according to the manufacturer's protocol. A total of $150 \mathrm{ng}$ of purified and sequencing-

162 verified entry vector together with $150 \mathrm{ng}$ of pcDNA3-GW-DEST vector were used for preparation of

163 the pcDNA3-PDLIM2-GW-DEST destination plasmid, and the LR recombination reaction was

164 performed according to the Gateway technology manual (Thermo Fisher Scientific). Chemically

165 competent E. coli TOP10 cells were used again for preparation and amplification of the resulting

166 destination plasmid that was subsequently purified by the Qiagen Plasmid Maxi Kit (Qiagen). The

167 resulting destination plasmid was stored at $-20{ }^{\circ} \mathrm{C}$.

168 Construction of lentiviral plasmids and lentiviruses and generation of a stably transduced 169 MCF7-PDLIM2 cell line

170 The lentiviral vector pLENTI-PDLIM2 was prepared in-house according to Gateway® Technology 171 with the Clonase ${ }^{\circledR}$ II user guide (Invitrogen, 25-0749 MAN0000470). The production of lentiviruses 172 was performed according to the ViraPower ${ }^{\mathrm{TM}}$ Lentiviral Expression Systems user manual (Invitrogen, 173 25-0501 MAN0000273). Transduction of MCF-7 cells and selection of stably transfected clones were 174 performed according to the ViraPower ${ }^{\mathrm{TM}}$ Lentiviral Expression Systems user manual (Invitrogen, 25175 0501 MAN0000273).

176 Cell transfection

177 For PDLIM2 suppression, cells were transfected using the Amaxa cell line nucleofector kit

$178 \mathrm{~V}$ (LonzaBio). A total of $1.0 \times 10^{6}$ cells cultivated to $70 \%$ confluence were harvested and resuspended 
in $100 \mu \mathrm{l}$ of AMAXA buffer $\left(4 \mathrm{mM} \mathrm{KCl}, 10 \mathrm{mM} \mathrm{MgCl} 2,120 \mathrm{mM} \mathrm{NaH} \mathrm{PO}_{4} / \mathrm{Na}_{2} \mathrm{HPO}_{4}, 10 \mathrm{mM}\right.$ HEPES pH 7.2) together with either anti-PDLIM2 siRNA or control siRNA at a concentration of 600 nM. T024 and P020 transfection programs were used for the transfection of MCF 10A and MCF7 cells, respectively. Plasmid transfection using the polyethylene imine (PEI) method based on lipofection was used. Cells were cultivated on 6-cm Petri dishes to $60-70 \%$ confluence, and $5 \mu \mathrm{g}$ of specific or control plasmid was resuspended together with $15 \mu$ l of PEI (working solution $1 \mu \mathrm{g} / \mu 1$ in water, $\mathrm{pH} 7$ ) in $0.5 \mathrm{ml}$ of serum-free medium, incubated for 15 minutes at room temperature, poured onto a dish and further cultivated for 24,48 or 72 hours.

\section{SDS PAGE and immunoblotting}

Cell lysates for SDS PAGE were prepared using hot $\left(95^{\circ} \mathrm{C}\right)$ sample buffer $(10 \%$ glycerol, $2 \%$ bromophenol blue, $62.5 \mathrm{mM}$ Tris $\mathrm{HCl} \mathrm{pH} 6.8,2 \%$ SDS pH 6.8, 5\% mercaptoethanol). SDS PAGE with a 5\% stacking gel and $10 \%$ running gel was used for separation as described previously [14]. Protein lysates in the amount of $20 \mu \mathrm{g}$, determined by an RC-DC Protein Assay (Bio-Rad), were run in the gels and wet-transferred onto PVDF membranes. Membranes were then blocked for 1 hour in PBS+0.1\% Tween $20\left(2.68 \mathrm{mM} \mathrm{KCl}, 0.137 \mathrm{M} \mathrm{NaCl}, 6.45 \mathrm{mM} \mathrm{Na}_{2} \mathrm{HPO}_{4} .12 \mathrm{H}_{2} \mathrm{O}, 1.47 \mathrm{mM} \mathrm{KH}_{2} \mathrm{PO}_{4}\right.$, $0.89 \mathrm{mM}$ Tween 20) containing 5\% nonfat milk and incubated with primary antibody (at the appropriate dilution, see above) at $4{ }^{\circ} \mathrm{C}$ overnight. After incubation, membranes were washed two secondary antibody (1:1000) at room temperature for 1 hour and washed again. After 5 min of incubation of membranes with ECL solution (10 mM luminol, $0.5 \mathrm{mM}$ EDTA, $405 \mu \mathrm{M}$ coumaric acid, $200 \mathrm{mM}$ Tris $\mathrm{pH}$ 9.4, $8 \mathrm{mM}$ sodium perborate tetrahydrate, $50 \mathrm{mM}$ sodium acetate), immunoreactive proteins were visualized by enhanced chemiluminescence (ECL) solution using a CCD camera (Alpha Innotech FluorChem ${ }^{\mathrm{TM}} \mathrm{SP}$, Quansys Biosciences, USA).

\section{Young's modulus mapping by Atomic Force Microscopy}

Young's modulus mapping was performed using JPK NanoWizard 3 (JPK, Berlin, Germany) on a bioAFM microscope, similar to previous publications [15-17]. A non-coated silicon nitride AFM 
probe Hydra 2R 100N (AppNano, Mountain View, CA, USA) equipped with a pyramidal silicon tip

was used for all experiments (side angle $18^{\circ}$ ). The sensitivity and cantilever spring constant were calibrated by the recommended routine procedure. The $64 \times 64$ point maps of force distance curves (setpoint $1 \mathrm{nN}, \mathrm{Z}$ length $15 \mu \mathrm{m}$, time per curve $0.5 \mathrm{~s}$ ) were measured. The recorded FD curves were fitted with the Bilodeau modification [18] of the Hertzian model in AtomicJ software [19]. Final visualization of the images and stiffness maps was performed with Gwyddion software ver. 2.44 [20]. Further details are provided in the Additional file 15: Methods S1.

\section{TGFß1 treatment and hypoxia}

213 EMT in cells was induced by TGF $\beta 1$ treatment or hypoxic conditions. For PDLIM2 protein level induction and monitoring, TGF $\beta 1$ was added to the complete culture medium to a final concentration of $1 \mathrm{ng} / \mathrm{ml}$, and the cells were cultivated for 24 hours. For cell morphology changes and monitoring, TGF $\beta 1$ at $10 \mathrm{ng} / \mathrm{ml}$ was added to serum-free medium after 16 hours of serum starvation, and the cells were cultivated for 48 hours [21]. Control cells were cultivated in medium without TGF $\beta 1$. For induction of EMT by hypoxia, cells were cultivated in a hypoxic culture hood (Biospherix Xvivo X3, Biospherix) under a $2 \%$ concentration of $\mathrm{O}_{2}$ for 48,72 or 96 hours.

\section{Migration and invasion assay}

Real-time measurements of cell migration and invasion were performed using the CIM-Plate 16 module of an xCELLigence System RTCA DP real-time cell analyzer (Roche, UK). For invasion measurement, the top side of the polycarbonate membrane in the upper chamber wells was coated with Culturex®Basement membrane extract (Trevigen, USA) diluted 1:50 with Coating buffer (Trevigen, USA) 4 hours prior to the experiment. The CIM plates were then prepared by the addition of $170 \mu \mathrm{L}$ of corresponding medium (with 10\% FBS as the chemoattractant) into twelve wells of the lower chamber; four wells filled with $170 \mu \mathrm{L}$ of serum-free medium served as controls to determine the background signal. Each well of the upper chamber was filled with $30 \mu \mathrm{L}$ of serum-free medium. The plates were inserted into the xCELLigence station in the culture hood $\left(21 \% \mathrm{O}_{2}, 5 \% \mathrm{CO}_{2}, 37{ }^{\circ} \mathrm{C}\right)$, and 
231 for migration and $1 \times 10^{5}$ cells per well for invasion) were then added to the wells of the upper chamber

232 in $100 \mu \mathrm{L}$ of serum-free medium, and the plate was equilibrated again for $30 \mathrm{~min}$ at room temperature

233 and inserted into the xCELLigence once again before the start of measurements. The detailed

234 arrangement of the plates is shown in Additional file 1: Figure S1. The xCELLigence analyzer was set

235 to measure the impedance every $15 \mathrm{~min}$ for 24 hours. Normalized cell indexes (CI) were then

236 calculated as a variable corresponding to the number of migrating or invading cells and statistically

237 evaluated (part "Statistical analysis").

238 Migration and invasion of cells were also measured using a 96-well Transwell assay (Trevigene,

239 USA). The Transwell assay consists of upper and lower chambers (each with 96 wells) separated by a

240 porous polyethylene terephthalate (PET) membrane (pore size $8 \mu \mathrm{m}$ ) localized on the bottom of the

241 upper chamber wells. For migration measurement, $100 \mu \mathrm{l}$ of medium containing 10\% FBS (used as a

242 chemoattractant) was applied to the lower chamber wells, and wells were filled with $100 \mu 1$ of serum-

243 free medium were used as controls. Cells $\left(5 \times 10^{4}\right.$ cells per well for migration and $1 \times 10^{5}$ cells per well

244 for invasion; see Additional file 1: Figure S1 for plate design) were resuspended in serum-free

245 medium and added to the upper chamber wells. After incubation in a culture hood $\left(21 \% \mathrm{O}_{2}, 5 \% \mathrm{CO}_{2}\right.$,

$24637^{\circ} \mathrm{C}$ ) for 24 hours, upper and lower chamber wells were rinsed, cells in the upper chamber wells

247 were washed away and the migrated or invasive cells on the lower membrane surface were stained

248 using Calcein AM according to the manufacturer's protocol. After 1 hour of incubation in the culture

249 hood in the dark, the fluorescence of converted calcein was measured using a Tecan Infinite M100 Pro

250 (Life Sciences) with an excitation wavelength of $495 \mathrm{~nm}$ and emission wavelength of $515 \mathrm{~nm}$. The

251 number of cells migrating or invading across the membrane was quantified according to fluorescence

252 values and statistically evaluated (part "Statistical analysis"). The invasion assay was performed

253 equivalently to the migration measurement assay but with coating of the top side of the polycarbonate

254 filter in the upper chamber wells with Culturex ${ }^{\circledR}$ Basement membrane extract.

255 Each experiment was performed with two biological replicates (cells grown on independent plates) per

256 condition with three technical replicates (wells) for each biological replicate. Two independent

257 experiments were performed per comparison. 


\section{Adhesion assay}

259 To measure adhesion in monolayer culture, cells in corresponding medium were seeded at $1 \times 10^{5}$ cells

260 per well in triplicate in a 6-well plate. After $30 \mathrm{~min}$, the medium was completely removed from the

261 wells, and unattached cells in the medium were counted using a Bürker chamber. The adhesion of cells

262 was based on the amount of unattached cells, which was statistically evaluated (part "Statistical

263 analysis"). Each experiment was performed three times on independent plates per comparison.

\section{Proliferation assay}

265 To measure proliferation in monolayer culture, cells in corresponding medium were seeded at $2662 \times 10^{4}$ cells per well in triplicate in a 96-well plate. After 24 hours, cells were treated with resazurin $267(1 \mathrm{mg} / \mathrm{ml})$ and incubated for $150 \mathrm{~min}$. After the incubation period, the fluorescence of resorufin was 268 measured using a Tecan Infinite M100 Pro, and measurement was performed for 16 spots per well 269 (excitation wavelength $573 \mathrm{~nm} /$ emission wavelength $583 \mathrm{~nm}$ ) and statistically evaluated. Each 270 experiment was performed three times on independent plates per comparison.

\section{Statistical analysis}

272 STATISTICA software version 12 was used for the statistical analyses for Figs. 3A-B and 5A. Data 273 were reported as the mean $+/-1.96 *$ (standard deviation) corresponding to $95 \%$ confidence intervals; 274 Student's t-test was used to assess the significance of differences between two groups, and p-values 275 below 0.05 were considered significant. For AFM evaluation in Fig. 1E, the Mann-Whitney test was 276 performed in $\mathrm{R}$ version 3.5.3., and p-values below 0.05 were considered significant. For the remaining 277 statistical analyses, Student's t-test in Microsoft Excel was applied, and p-values below 0.05 were 278 considered significant. 
PDLIM2 protein levels are positively coregulated with epithelial-to-mesenchymal transition in

\section{MCF7 breast cancer cells}

282

Based on the results of our previous combined proteomics-transcriptomics study [5], we hypothesized that PDLIM2 may act as an oncoprotein in luminal A breast tumors. To test this hypothesis in vitro, we selected MCF7 human breast cancer cells as a model of luminal A breast cancer [22-24], modulated PDLIM2 protein levels and evaluated molecular and cellular changes caused by these modifications. First, overexpression of PDLIM2 decreased the epithelial markers E-cadherin, $\beta$ catenin and keratin-18 (KRT18) and increased levels of the $\beta 1$-integrin pathway regulator FAK (Fig. 1A and Additional file 2: Figure S2), indicating epithelial-to-mesenchymal transition (EMT) was connected with PDLIM2. On the other hand, PDLIM2 expression suppression by small interference RNA (siRNA; Fig. 1A and Additional file 2: Figure S2) increased E-cadherin, $\beta$-catenin and KRT18 and decreased FAK levels, indicating mesenchymal-to-epithelial transition (MET) was initiated by PDLIM2 suppression. The ability of PDLIM2 to affect cell morphology was observed in MCF7 cells stably transduced with PDLIM2 vector (compared to parental MCF7 as a control) using optical microscopy, showing that MCF7-PDLIM2 cells acquire similar morphology as MCF7 cells after TGFß1-induced EMT (Fig. 1B). A similar pattern was evident from the atomic force microscopy (AFM) data, showing MCF7-PDLIM2 cells had higher stiffness based on Young's modulus relative to parental MCF7 cells (Fig. 1E), similarly as after TGFß1-induced EMT (Figs. 1B-F, Additional file 12: Table S1 and Additional file 16: Dataset S1). All of these data suggest that PDLIM2 might play a significant role in the regulation of EMT in MCF7 cells.

EMT induction by TGFß1 and hypoxia increases PDLIM2 levels, and PDLIM2 overexpression augments CA9 and reduces p53 levels as well as p53 phosphorylation (S20) in MCF7 breast cancer cells

To investigate how PDLIM2 is affected by EMT, we induced EMT by TGF $\beta 1$ ( $1 \mathrm{ng} / \mathrm{ml}$ for 24 hours) or by long-term exposure to hypoxia ( $2 \% \mathrm{O}_{2}$ for 96 hours) and monitored how PDLIM2 responds. 
Both treatments led to elevated PDLIM2 protein levels, and successful induction of EMT was confirmed by decreased levels of the epithelial markers E-cadherin, $\beta$-catenin and KRT18 (Fig. 2A and Additional file 4: Figure S4). Notably, we observed that shorter exposure times to hypoxic conditions (48 and 72 hours) were still not able to decrease levels of epithelial markers and induce EMT (see Additional file 5: Figure S5); however, PDLIM2 levels increased (Fig. 2B and Additional file 5: Figure S5), indicating that not only EMT but also hypoxia itself upregulates PDLIM2 levels. Moreover, levels of carbonic anhydrase-9 (CA9), a marker of the response to hypoxic conditions, were elevated in MCF7 cells with overexpressed PDLIM2 (Fig. 2C and Additional file 6: Figure S6).

In addition to TGF $\beta 1$ and hypoxia-induced EMT, we were interested in whether PDLIM2 functionally interacts with other key cancer players, including p53 and p65. We found that PDLIM2 overexpression decreased both the p53 total protein level as well as its serine 20 phosphorylated, active form (p-p53 (S20)) (Fig. 2D and Additional file 7: Figure S7). On the other hand, the level of p65 protein, a key member of the canonical NF-kB pathway, was not affected by any of these treatments, nor by overexpression or suppression of PDLIM2 (see Fig. 2D and Additional file 7: Figure S7).

\section{PDLIM2 overexpression increases both migration and invasion of MCF7 breast cancer cells}

To further verify the pro-tumorigenic role of PDLIM2 on cellular levels, we examined its effect on the migration and invasion of the MCF7 cells. PDLIM2 overexpression increased the migration capabilities of these cells as observed by real-time measurement using the xCELLigence system $\left(\mathrm{p}=2.8 \times 10^{-4}\right)$ and independently confirmed using a Transwell assay with end-point detection $\left(\mathrm{p}=3.6 \times 10^{-5}\right)$ (Fig. 3A). Overexpression of PDLIM2 also had a similar effect on the invasion of MCF7 cells measured using xCELLigence $\left(\mathrm{p}=3.9 \times 10^{-4}\right)$ and the Transwell assay $\left(\mathrm{p}=1 \times 10^{-5}\right)$ (Fig. 3B). Our results suggest that PDLIM2 is relevant for regulation of the migration and invasiveness of MCF7 cells. 
PDLIM2 overexpression diminishes cell adhesion and increases proliferation of MCF7 cells, while suppression of PDLIM2 has the opposite effect

331 Next, we investigated the consequences of PDLIM2 modulation on the adhesion and proliferation of

332 MCF7 cells. Suppression of PDLIM2 by siRNA significantly augmented the adhesion of MCF7 cells

$333\left(* \mathrm{p}=1 \times 10^{-5}\right)$ compared to control cells; on the other hand, specific overexpression of PDLIM2 334 considerably decreased adhesion $\left(\mathrm{p}=1 \times 10^{-5}\right)$ (Fig. 3C). PDLIM2 suppression also substantially 335 diminished the proliferation of MCF7 cells $\left(\mathrm{p}=1 \times 10^{-5}\right)$, in contrast to the dramatic increase in the 336 proliferation of the MCF7 cells with overexpressed PDLIM2 ( $\left.\mathrm{p}=1 \times 10^{-5}\right)$ (Fig. 3D). These results 337 indicate involvement of PDLIM2 in the regulation of MCF7 cell adhesion and proliferation.

PDLIM2 overexpression is important for maintenance of the epithelial phenotype in MCF10A human immortalized epithelial breast cells, while PDLIM2 suppression has opposite consequences

To ascertain whether the effects related to PDLIM2 levels described in sections above are of general validity or are context-dependent, we selected another model, MCF10A immortalized human epithelial breast cells. We either overexpressed or suppressed PDLIM2 in these cells and monitored the effects of these changes on molecular and cellular levels. The effects of overexpression and suppression of PDLIM2 on EMT markers are shown in Fig. 4A and Additional file 8: Figure S8: overexpression led to augmentation of the epithelial marker E-cadherin and decreases in the mesenchymal markers vimentin and $\mathrm{N}$-cadherin, as well as the $\beta 1$-integrin pathway regulator FAK, indicating MET and maintenance of the epithelial phenotype. PDLIM2 suppression had the opposite effect: E-cadherin levels were decreased, and levels of the mesenchymal markers vimentin and $\mathrm{N}$ cadherin as well as FAK were increased, indicating EMT. These results suggest that PDLIM2 is important for maintaining the epithelial phenotype of MCF10A cells. 
To investigate how EMT affects PDLIM2 in MCF10A cells, we induced EMT by treatment with TGFß1 (1 ng/ml for 24 hours) and monitored PDLIM2 protein levels. As shown in Fig. 4B and Additional file 9: Figure S9, PDLIM2 protein levels were downregulated after EMT induction in MCF10A cells, in a distinct manner compared to that of MCF7 cells. Successful EMT induction was confirmed by decreased levels of E-cadherin and increased levels of vimentin and N-cadherin. We also attempted to induce EMT by exposing the MCF10A cells to hypoxic conditions; however, we did not observe any changes in E-cadherin and vimentin levels as well as in PDLIM2 protein levels (see Additional file 10: Figure S10A and S10B). Additionally, we did not observe any change in CA9 levels after PDLIM2 modulation (see Additional file 10: Figure S10C). These results confirm the importance of PDLIM2 in the maintenance of the epithelial phenotype and indicate that PDLIM2 does not play a significant role in the response to hypoxic conditions in MCF10A cells.

PDLIM2 overexpression decreases p53 (S20) phosphorylation in MCF10A cells analyzed its effect on p53 levels, p53 phosphorylation (S20) and p65 protein levels. In contrast to MCF7 cells, overexpression of PDLIM2 had no effect on p53 levels (see Fig. 4A and Additional file 8: Figure S8); nevertheless, the active form of this protein, p-p53 (S20), was augmented (Fig. 4A and Additional file 8: Figure S8). The level of p65 was not affected by overexpression or suppression of PDLIM2 (see Fig. 4A and Additional file 8: Figure S8). These results suggest a tumor suppressive role of PDLIM2 in MCF10A cells. cells To validate the distinct role of PDLIM2 in MCF10A cells at the cellular level, we examined its effect on the migration and adhesion of MCF10A cells. PDLIM2 suppression by siRNA was accompanied by significant augmentation of the migration abilities of the MCF10A cells relative to cells with 
378

endogenous protein levels, as revealed by Transwell assay $\left(\mathrm{p}<1 \times 10^{-5}\right)$ (Fig. 5A, conditions A, C and E). Conversely, overexpression of PDLIM2 significantly decreased the migration abilities of the MCF10A cells $\left(\mathrm{p}<1 \times 10^{-5}\right)$ relative to cells with endogenous protein levels (Fig. 5A, conditions B, D and E). As shown in Fig. 5B, PDLIM2 suppression significantly decreased the adhesion of MCF10A cells $\left(\mathrm{p}<1 \times 10^{-5}\right)$, while on the other hand, overexpression of this protein considerably augmented the adhesion of MCF10A cells $\left(\mathrm{p}<1 \times 10^{-5}\right)$ relative to control cells. These results further confirm the tumor-suppressive role of PDLIM2 in MCF10A cells and its context-dependent behavior.

\section{Analysis of breast cancer cell lines and tissues supports the dual role of PDLIM2 in breast cancer development}

Finally, comparison of PDLIM2 protein levels in other breast cancer cell lines (Additional file 11: Figure S11) showed that PDLIM2 levels were low in low invasive MCF7 breast cancer; however, higher PDLIM2 levels were found in highly invasive triple negative MDA-MB-231, supporting the connection of PDLIM2 to metastatic potential. Higher levels of PDLIM2 were also found in normal MCF10A cells (Additional file 11: Figure S11), in agreement with its tumor suppressor role in normal breast cells. This is in principal agreement with our breast cancer tissue data that showed a high PDLIM2 level in primary tumors forming lymph node metastases, but specifically in small (T1) luminal A grade 1 tumors (Additional file 13: Table S2), which represent the early phase of tumor development. Conversely, the epithelial marker KRT18 was significantly downregulated in PDLIM2rich luminal A tumors forming lymph node metastases (Additional file 14: Table S3), further supporting the PDLIM2 connection with mesenchymal phenotype in tissues. Taken together, these data suggest a connection between PDLIM2 and metastatic phenotype in luminal A tumors and its distinct roles in different phases of cancer development.

\section{DISCUSSION}

Deregulation of PDLIM2 has been associated with oncogenesis, including lymph node metastasis of breast cancer [5]. The PDLIM2 gene is repressed in different cancers, which implies its tumor suppressive role. Repression and a tumor suppressive role of PDLIM2 were observed in ATL induced 
by HTLV1 virus [26-29], Kaposi sarcoma [30], ovarian cancer [31], gastric cancer [32], colon cancer

405 [12], Hodgkin lymphoma [33] and breast cancer [34, 35]. In contrast to the above studies, a pro-

406 oncogenic role and enhanced expression of PDLIM2 were observed in castration-resistant prostate

407 cancer cells $[5,9,36]$, invasive breast cancer cell lines and breast carcinomas $[9,11]$. The aim of the study presented here was to understand the role of PDLIM2 at both the molecular and cellular levels in the breast cancer context in more detail using in vitro experiments.

\section{PDLIM2 role in MCF7 breast cancer cells}

411 Our data indicate a positive role for PDLIM2 in EMT induction (Fig. 1A and Additional file 2: Figure S2), which was previously described in DU145 prostate cancer cells and MDA-MB-231 highly invasive breast cancer cells $[9,36]$. We for the first time report this role in MCF7 cells, a model of luminal A tumors, confirming the previous data from our clinical set of luminal A breast cancer tissues [5]. Overexpression of PDLIM2 also denotes disturbance of the $\beta 1$-integrin pathway and loss of the epithelial phenotype via increased levels of FAK, the regulator of the $\beta 1$-integrin pathway [10]. Apart from the above, the stiffness of MCF7 cells was significantly augmented after PDLIM2 overexpression (Fig. 1B-C). Increased cell stiffness is typical for cells with a mesenchymal phenotype [28], which again supports the PDLIM2 role in EMT induction. Moreover, EMT induction by TGF $\beta 1$ treatment and/or long-term hypoxia increases PDLIM2 levels (Fig. 2A, Additional file 4: Figure S4).

Our experiments also revealed a reciprocal connection between PDLIM2 and the response to hypoxia completely new information that deserves further examination. Furthermore, the observed negative effects of PDLIM2 on the levels of proteins involved in DNA repair and cell cycle regulation via p53 and especially p-p53 (S20) [39-41] indicate the relation between PDLIM2 and these processes in PDLIM2 in the regulation of EMT induction and in the maintenance of the cellular phenotype in MCF7 cells. Additionally, involvement of PDLIM2 in the response to hypoxia and the effect of 
431 At the cellular level, we have clearly proven the positive effect of PDLIM2 on MCF7 cell migration,

432 invasiveness, and proliferation and the negative effect on MCF7 adhesive abilities (Fig. 3A-D).

433 Similar results were previously obtained with MCF7 [11], DU145 and MDA-MB-231 cells for

434 migration [9] and with CRPC cells for both migration and invasion [36]. A negative effect of PDLIM2

435 on adhesion and a positive effect on proliferation were already described in DU145 and MDA-MB-

436231 cells [9], and the positive effect of PDLIM2 on proliferation was observed in CRPC cells [36].

437 Migration and invasion are closely connected to EMT induction, and both are the key steps in 438 oncogenesis and metastasis formation [42-44]. The results observed at the cellular level are thus in 439 good agreement with the molecular-level data. Additionally, disruption of cell adhesion and increased 440 cell proliferation are the key signatures of oncogenesis [42]. In view of these facts, and in agreement 441 with previous studies, the cellular-level results bring additional support for the pro-oncogenic role of 442 PDLIM2 in luminal A breast cancer and functionally further validate our previous data from clinical 443 tissues [5].

444 PDLIM2 role in MCF10A normal epithelial breast cells

445 On the other hand, the potential tumor suppressive role of PDLIM2 was revealed in our experiments 446 using immortalized normal epithelial MCF10A cells. Our data indicate a negative role of PDLIM2 in 447 EMT induction, its importance for maintaining the epithelial phenotype of MCF10A cells and the 448 negative effect of EMT on PDLIM2 protein levels (Figs. 4A, 4B, Additional file 8: Figure S8 and 449 Additional file 9: Figure S9), distinct from MCF7 cells. These new findings are in good agreement 450 with the known role of PDLIM2 in maintaining breast epithelial cell polarity [10]. Overexpression of 451 PDLIM2 in MCF10A was further associated with increased p53 (S20) phosphorylation. This was 452 revealed for the first time and indicates a positive connection between PDLIM2, DNA repair and cell 453 cycle regulation in these cells (Fig. 4A, Additional file 8: Figure S8). Interestingly, no effect of 454 PDLIM2 on hypoxia and no effect of hypoxia on PDLIM2 levels were observed, suggesting different 455 and context-dependent roles of PDLIM2 in the response to hypoxic conditions (see Additional file 10:

456 Figure S10). It seems that PDLIM2 helps to induce a hypoxic response and supports the proliferation 457 of MCF7 cells; however, it may not be involved in hypoxic response regulation in MCF10A cells. In a 
broader context, PDLIM2 function in MCF10A cells is evidently highly distinct from that in MCF7 cells, being rather tumor suppressing. Furthermore, similar levels of PDLIM2 protein in invasive triple negative breast cancer cells (MDA-MB-231) and normal breast epithelial cells (MCF10A) (Additional file 11: Figure S11) indicate, in agreement with previous data [34], a significant role for PDLIM2 not only in MCF10A but also in invasive breast cancer cells. On the other hand, PDLIM2 levels were substantially lower in low invasive MCF7 cells (Additional file 11: Figure S11 and [34, 11]), suggesting that PDLIM2 is suppressed in a gap between neoplastically transformed and invasive breast cancer cells that undergo EMT. The tumor suppressive function of PDLIM2 in MCF10A cells was also evident in experiments at the cellular level. As shown for the first time here, PDLIM2 negatively regulates migration and positively regulates the adhesion of MCF10A cells (Fig. 5A-B). These effects are in agreement with the expected role of PDLIM2 in the maintenance of the epithelial phenotype and with its tumor-suppressive function in MCF10A cells. Altogether, these results give evidence for the dual and context-dependent role of PDLIM2, which acts as a possible tumor suppressor in normal epithelial cells (MCF10A) and as a potential oncoprotein in luminal A breast cancer (MCF7 cells), and suggest that PDLIM2 levels may fluctuate during oncogenesis.

\section{Context-dependent role of PDLIM2 in breast cancer progression}

Data presented in this study led us to the hypothesis that changes in PDLIM2 protein levels during breast cancer oncogenesis are context-dependent (Fig. 6). According to our data and several previous studies [9-11, 36, 37], we assume that newly transformed low-invasion breast cancer cells have reduced levels of PDLIM2. Overexpression of PDLIM2 levels in these cells led to a dramatic increase in their metastatic potential and cancer progression, demonstrating the oncoprotein role of PDLIM2 (Figs. 1-3, Additional file 2: Figure S2, Additional file 4: Figure S4, Additional files 5-7: Figures S5S7). According to our data (Additional file 11: Figure S11) and in agreement with others [9, 34], we further assume that highly invasive breast cancer cells express high levels of PDLIM2, and we expect that this could support them to form metastasis. However, these cells may undergo MET in the next step of the metastatic cascade, and PDLIM2 levels may diminish after successful metastatic colonization, supporting growth of the cells to build secondary tumors. In agreement with our previous 

tumors with increased metastatic potential. Inhibition of PDLIM2 protein in these tumors has the

487 potential to reduce migration, invasion and proliferation and augment adhesion properties due to phenotypic changes toward MET, which makes PDLIM2 an interesting target for further studies on its possible therapeutic application.

\section{CONCLUSION}

491 We demonstrate that PDLIM2 plays dual and context-dependent roles in breast cancer development:

492 PDLIM2 facilitates maintenance of the epithelial phenotype in normal breast MCF10A cells, but it 493 also promotes EMT in MCF7 breast cancer cells. PDLIM2 supports migration, invasion and 494 proliferation in MCF7 cells but blocks migration and supports the adhesion of MCF10A cells. Our

495 findings thus show that PDLIM2 has the potential to act as a tumor suppressor in MCF10A cells (a 496 model of normal epithelial breast cancer) but as an oncoprotein in MCF7 cells (model of luminal A 497 breast cancer). These observations are complementary and unravel previous contradictory findings in 498 the literature, leading us to the hypothesis that changes in PDLIM2 protein levels during oncogenesis 499 of breast cancer have a context-dependent nature. These data provide a basis for further interesting 500 investigations to determine whether PDLIM2 blocking might have potential therapeutic implications 501 in luminal A breast cancer.

\section{ABBREVIATIONS}

503 AFM: atomic force microscopy

504 ALP: actinin-associated LIM protein

505 CA9: carbonic anhydrase-9

506 E-cad: E-cadherin

507 EMT: epithelial-to-mesenchymal transition

508 FAK: focal adhesion kinase 
509 IGF-1R: insulin-like growth factor 1 receptor

$510 \quad$ KRT18: keratin-18

511 MET: mesenchymal-to-epithelial transition

$512 \quad$ N-cad: N-cadherin

513 PCNA: proliferating cell nuclear antigen

514 PDLIM2: PDZ and LIM domain protein 2

515 Vim: Vímentin

516 DECLARATIONS

517 Ethics approval and consent to participate

518 Not applicable.

519 Consent for publication

520 Not applicable.

521 Availability of data and materials

522 All the datasets used and/or analysed during the current study are available from the corresponding

523 author on reasonable request.

\section{Competing interests}

525 The authors declare that they have no competing interests.

526 Funding

527 This work was supported by the Czech Science Foundation, project No. 17-05957S. Parts of the work 528 were further supported by the Ministry of Education, Youth and Sports of the Czech Republic: the 529 experiments by J.M. at Masaryk Memorial Cancer Institute (MEYS - NPS I - LO1413), the work of 
531 research infrastructure, LM2015043).

\section{Authors' contributions}

533 J.M. designed, performed and evaluated experiments and drafted the manuscript, J.P. performed and

534 evaluated AFM experiments, P.B. ${ }^{1}$ prepared cells for optical microscopy and AFM and generated Fig.

535 S3, P.S. initiated AFM experiments and contributed to manuscript preparation, P.B. ${ }^{2}$ supervised the 536 study, manuscript preparation, acquired funding and approved the final manuscript.

\section{Acknowledgements}

538 We thank Dr. Petr Müller for his help with preparation of the plasmids and stably transduced cell line,

539 Zuzana Bertova for her technical assistance with AFM and Anna Pospisilova for data processing in

540 Fig. 1E.

\section{REFERENCES}

542 1. Ross JS, Hortobagyi GN. Molecular Oncology of Breast Cancer. Sudbury: Jones \& Barlett 543 Publishers; 2005.

544 2. Cress AE, Nagle RB. Cell Adhesion and Cytoskeletal Molecules in Metastasis. Dordrecht: Springer; 5452006.

546 3. Mansel RE, Fodstad O, Jiang WG. Metastasis of Breast Cancer. Dordrecht: Springer; 2007.

547 4. Harris L, Fritsche H, Mennel R, Norton L, Ravdin P, Taube S, et al. American Society of Clinical 548 Oncology 2007 update of recommendations for the use of tumor markers in breast cancer. J Clin 549 Oncol. 2007;25:5287-312.

550 5. Bouchal P, Dvorakova M, Roumeliotis T, Bortlicek Z, Ihnatova I, Prochazkova I, et al. Combined 551 Proteomics and Transcriptomics Identifies Carboxypeptidase B1 and Nuclear Factor $\kappa \mathrm{B}$ (NF- $\mathrm{kB})$ 552 Associated Proteins as Putative Biomarkers of Metastasis in Low Grade Breast Cancer. Moll Cell 553 Proteomics. 2015;14:1814-30. 
554 6. Torrado M, Senatorov VV, Trivedi R, Fariss RN, Tomarev SI. Pdlim2, a novel PDZ-LIM domain 555 protein, interacts with alpha-actinins and filamin A. Invest Ophthalmol Vis Sci. 2004;45:3955-63.

556 7. Healy NC, O'Connor R. Sequestration of PDLIM2 in the cytoplasm of monocytic/macrophage cells 557 is associated with adhesion and increased nuclear activity of NF-kappaB. J Leukoc Biol. 2009;85:48155890.

559 8. te Velthuis AJ, Bagowski CP. PDZ and LIM domain-encoding genes: molecular interactions and 560 their role in development. ScientificWorldJournal. 2007;7:1470-92.

561 9. Bowe RA, Cox OT, Ayllón V, Tresse E, Healy NC, Edmunds SJ, et al. PDLIM2 regulates 562 transcription factor activity in epithelial-to-mesenchymal transition via the COP9 signalosome. Mol 563 Biol Cell. 2014;25:184-95.

564 10. Deevi RK, Cox OT, O'Connor R. Essential function for PDLIM2 in cell polarization in three565 dimensional cultures by feedback regulation of the $\beta 1$-integrin-RhoA signaling axis. Neoplasia. $566 \quad 2014 ; 16: 422-31$.

567 11. Loughran G, Healy NC, Kiely PA, Huigsloot M, Kedersha NL, O'Connor R. Mystique is a new insulin-like growth factor-I-regulated PDZ-LIM domain protein that promotes cell attachment and migration and suppresses Anchorage-independent growth. Mol Biol Cell. 2005;16:1811-22. 12. Qu Z, Yan P, Fu J, Jiang J, Grusby MJ, Smithgall TE, et al. DNA methylation-dependent repression of PDZ-LIM domain-containing protein 2 in colon cancer and its role as a potential therapeutic target. Cancer Res. 2010;70:1766-72. 13. Maryas J, Bouchal P. PDLIM2 and its Role in Oncogenesis - Tumor Suppressor or Oncoprotein?.

$574 \quad$ Klin Onkol. 2015;28:40-6.

575 14. Bouchal P, Dvorakova M, Scherl A, Garbis SD, Nenutil R, Vojtesek B. Intact protein profiling in 576 breast cancer biomarker discovery: protein identification issue and the solutions based on 3D protein 577 separation, bottom-up and top-down mass spectrometry. Proteomics. 2013;13:1053-58. 15. Golan M, Jelinkova S, Kratochvilova I, Skladal P, Pesl M, Rotrekl V, et al. AFM Monitoring the 579 Influence of Selected Cryoprotectants on Regeneration of Cryopreserved Cells Mechanical Properties. $580 \quad$ Front Physiol. 2018;29:e804. 
581 16. Golan M, Pribyl J, Pesl M, Jelinkova S, Acimovic I, Jaros J, et al. Cryopreserved cells 582 regeneration monitored by atomic force microscopy and correlated with state of cytoskeleton and 583 nuclear membrane. IEEE Trans Nanobioscience. 2018;17:485-97. cell mechanics by controlling focal adhesion assembly. Nat Commun. 2017;15:e15321. 18. Bilodeau GG. Regular Pyramid Punch Problem. J Appl Mech. 1992;59:519-23. force curves. Rev Sci Instrum. 2014;85:e063703.

20. Necas D, Klapetek P. Gwyddion: an open-source software for SPM data analysis. Centr Eur J Phys. 2012;10:181-88. mediated by AP1-dependent EpCAM expression in MCF-7 cells. J Cell Physiol. 2015;230:775-82. tissue derived cell lines. Dis Markers. 2001;17:99-109.

23. Lacroix M, Leclercq G. Relevance of breast cancer cell lines as models for breast tumours: an update. Breast Cancer Res Treat. 2004;83:249-89. Experience in Research. Anticancer Res. 2015;35:3147-54. 25. Maryas J, Faktor J, Capková L, Muller P, Skladal P, Bouchal P. Pull-down Assay on Streptavidin Beads and Surface Plasmon Resonance Chips for SWATH-MS-based Interactomics. Cancer 601 Genomics Proteomics. 2018;15:395-404.

602 26. Yan P, Fu J, Qu Z, Li S, Tanaka T, Grusby MJ, et al. PDLIM2 suppresses human T-cell leukemia 603 virus type I Tax,-mediated tumorigenesis by targeting Tax into the nuclear matrix for proteasomal 604 degradation. Blood. 2009;113:4370-80.

605 27. Yan P, Qu Z, Ishikawa C, Mori N, Xiao G. Human T-cell leukemia virus type I-mediated 606 repression of PDZ-LIM domain-containing protein 2 involves DNA methylation but independent of 607 the viral oncoprotein tax. Neoplasia. 2009;11:1036-41. 

mediated tumorigenesis. Oncogene. 2010;29:3499-507. type 1 bZIP factor selectively suppresses the classical pathway of NF-kappaB. Blood. 2009;113:275564.

613 30. Sun F, Xiao Y, Qu Z. Oncovirus Kaposi sarcoma herpesvirus (KSHV) represses tumor suppressor 614 PDLIM2 to persistently activate nuclear factor $\kappa \mathrm{B}(\mathrm{NF}-\mathrm{\kappa B})$ and STAT3 transcription factors for 615 tumorigenesis and tumor maintenance. J Biol Chem. 2015;290:7362-68.

616 31. Zhao L, Yu C, Zhou S, Lau WB, Lau B, Luo Z, et al. Epigenetic repression of PDZ-LIM domaincontaining protein 2 promotes ovarian cancer via NOS2-derived nitric oxide signaling. Oncotarget. 2015;7:1408-20. metastasis and tumorigenicity in gastric cancer. Oncotarget. 2016;7:30276-94. the putative ubiquitin-E3 ligase PDLIM2 in classical Hodgkin and anaplastic large cell lymphoma. Leukemia. 2016;31:602-13.

624 34. Qu Z, Fu J, Yan P, Hu J, Cheng SY, Xiao G. Epigenetic repression of PDZ-LIM domain625 containing protein 2: implications for the biology and treatment of breast cancer. J Biol Chem. 2010;28:11786-92. expression is driven by vitamin $\mathrm{D}$ and is involved in the pro-adhesion, and anti-migration and invasion activity of vitamin D. Oncogene. 2014;33:1904-11. Reduces Tumor Growth and Invasiveness of Human Castration-Resistant Prostate Cancer-Like Cells. The Prostate. 2016;76:273-85.

633 37. Xu W, Mezencev R, Kim B, Wang L, McDonald J, Sulchek T. Cell Stiffness is a Biomarker of the 634 Metastatic Potential of Ovarian Cancer Cells. PLOS ONE. 2012;7:e46609. 
635 38. Carnero A, Lleonart M. The hypoxic microenvironment: A determinant of cancer stem cell 636 evolution. Bioessays. 2016;38:65-74.

637 39. Chehab NH, Malikzay A, Stavridi ES, Halazonetis TD. Phosphorylation of Ser-20 mediates 638 stabilization of human p53 in response to DNA damage. Proc Natl Acad Sci U S A. 1999;96:1377763982.

640 40. Xie S, Wu H, Wang Q, Cogswell JP, Husain I, Conn C, et al. Plk3 functionally links DNA damage 641 to cell cycle arrest and apoptosis at least in part via the p53 pathway. J Biol Chem. 2001;276:4330564212.

643 41. Louria-Hayon I, Grossman T, Sionov RV, Alsheich O, Pandolfi PP, Haupt Y. The promyelocytic 644 leukemia protein protects p53 from Mdm2-mediated inhibition and degradation. J Biol Chem. $645 \quad 2003 ; 278: 33134-41$

646 42. Polireddy K, Chen Q. Cancer of the Pancreas: Molecular Pathways and Current Advancement in 647 Treatment. J Cancer. 2016;7:1497-514.

648 43. Kalluri R, Weinberg RA. The basics of epithelial-mesenchymal transition. J Clin Invest. $649 \quad 2009 ; 119: 1420-28$.

650 44. Felipe Lima J, Nofech-Mozes S, Bayani J, Bartlett JM. EMT in Breast Carcinoma-A Review. J 651 Clin Med. 2016;5:e65.

652 ADDITIONAL INFORMATION

653 Additional file 1: Figure S1.pdf. A common schema of xCELLigence and/or Transwell experiments 654 for the measurement of cell migration and invasion.

655 Additional file 2: Figure S2.pdf. Effects of altered PDLIM2 protein levels on EMT markers in MCF7 656 cells.

657 Additional file 3: Figure S3.pdf. Confirmatory immunoblotting of EMT induction in MCF7658 PDLIM2 and parental MCF7 cells after TGF $\beta 1$ treatment and before AFM measurements.

659 Additional file 4: Figure S4.pdf. Effect of EMT induction on PDLIM2 protein levels in MCF7 cells. 
660 Additional file 5: Figure S5.pdf. Effects of short-term exposure to hypoxia $\left(2 \% \mathrm{O}_{2}\right.$ for 48 and 72 661 hours) on EMT markers and PDLIM2 protein levels in MCF7 cells.

662 Additional file 6: Figure S6.pdf. Effects of altered PDLIM2 protein levels on the hypoxic marker 663 carbonic anhydrase 9 (CA9) in MCF7 cells.

664 Additional file 7: Figure S7.pdf. Effects of altered PDLIM2 protein levels on p53 levels, p53 (S20) 665 phosphorylation and p65 levels in MCF7 cells.

666 Additional file 8: Figure S8.pdf. Effect of altered PDLIM2 protein levels on EMT markers, p53, p667 p53 (S20) and p65 in MCF10A cells.

Additional file 9: Figure S9.pdf. Effects of EMT induction on PDLIM2 protein levels in MCF10A cells.

Additional file 10: Figure S10.pdf. Effect of short term and long term expositions to hypoxic conditions on EMT induction and effect of PDLIM2 alterations on CA9 in MCF10A cells.

Additional file 11: Figure S11.pdf. PDLIM2 protein levels in different breast cell lines (MCF7,

Additional file 12: Table S1.docx. Statistics of average height and Young's modulus of the cells measured by AFM.

Additional file 13: Table S2.docx. Connection between PDLIM2 and clinicopathological parameters of breast cancer based on our previous combined proteomics and transcriptomics study ( $\mathrm{n}=96$ in total) [5].

Additional file 14: Table S3.docx. iTRAQ-2DLC-MS/MS quantitative protein-level data for PDLIM2 and epithelial and mesenchymal marker proteins in lymph node-positive $(n=24)$ vs. negative $(\mathrm{n}=96$ in total) $[5]$. 
684 Additional file 16: Dataset S1.pdf. AFM data for all measurements.

685 Additional file 17: Dataset S2.pdf. xCELLigence data for MCF7 migration and invasion 686 measurements.

687 Additional file 18: Dataset S3.xls. Transwell assay data for MCF7 migration and invasion 688 measurements.

689 Additional file 19: Dataset S4.xls. Transwell assay data for MCF10A migration measurements. 
A)
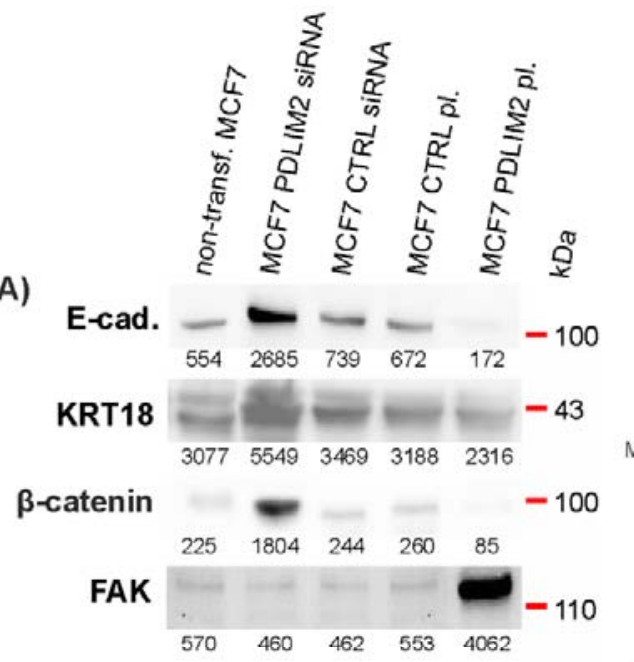

PDLIM2 $=-37 \begin{gathered}\text { MCF7 } \\ \text { PDLIM2 }\end{gathered}$

PCNA $\begin{array}{lllll}668 & 640 & 678 & 694 & 683\end{array}-28$

C)

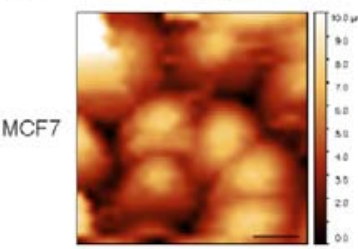

TGF $\beta 1$ -
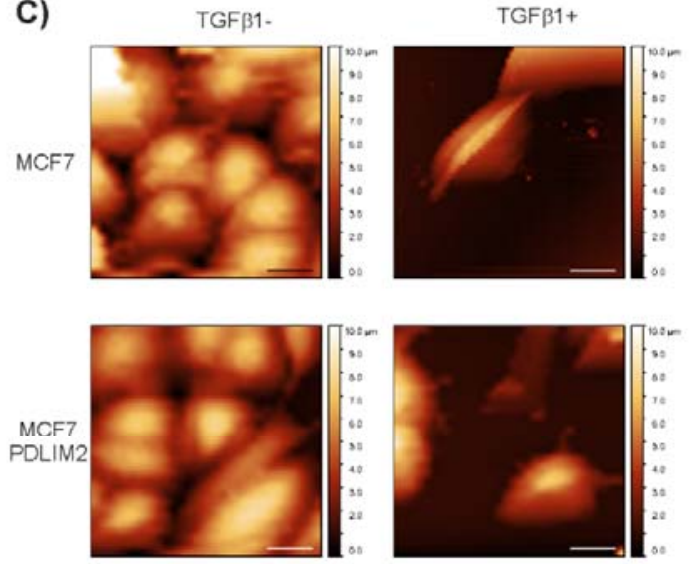

E)
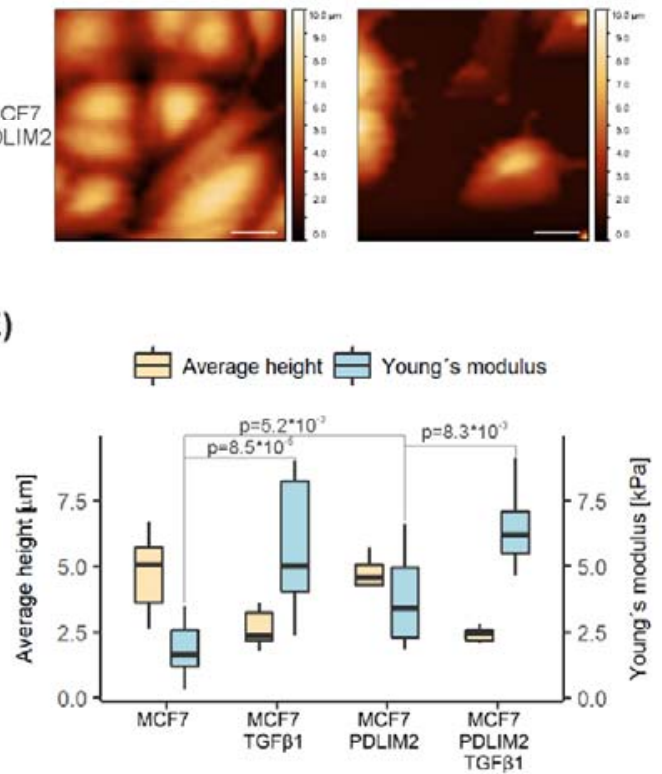

B)
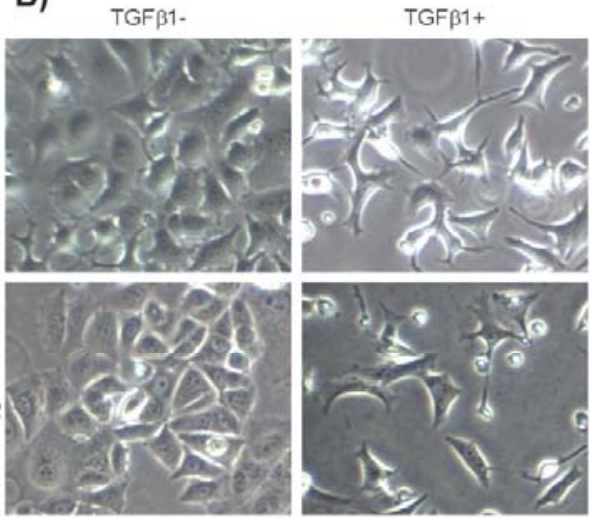

D) TGF 1 1-

TGF $\beta 1+$
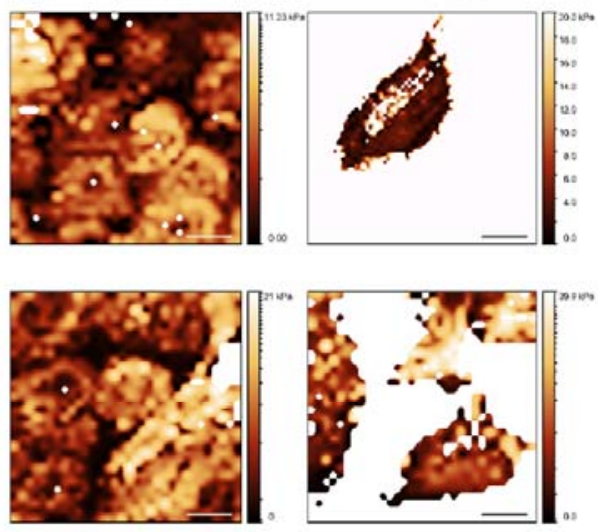

F)

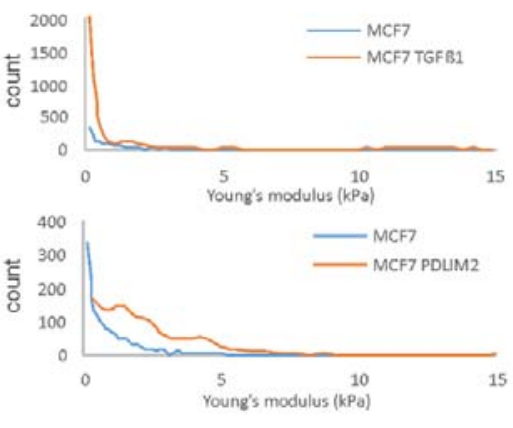

Fig. 1: Effect of PDLIM2 protein level modulations on EMT markers and MCF7 cell stiffness. (A) Effect of modulated PDLIM2 levels on the EMT markers E-cadherin (E-cad.), keratin-18 (KRT18) and $\beta$-catenin as well as focal adhesion kinase (FAK) in MCF7 cells. PDLIM2 protein levels were modulated by siRNA suppression (MCF7 PDLIM2 siRNA) compared to the control (MCF7 CTRL siRNA) or by PDLIM2 overexpression (MCF7 PDLIM2 pl.) compared to the control (MCF7 CTRL pl.). Proliferating cell nuclear antigen (PCNA) was used as a loading control [25]. Numbers 
under the protein bands represent their integral optical density $\left(\mathrm{INT}^{*} \mathrm{~mm}^{2}\right)$. Blots are representative of two independent experiments (biological replicates), see Additional file 2: Figure S2 for both biological replicates. (B) Representative photos of MCF7 parental cells and stably transduced MCF7PDLIM2 cells after TGF $\beta 1$ treatment (TGF $\beta 1+$ ) in comparison with control untreated cells (TGF $\beta 1-)$. Magnification 50x. (C) Distribution of cell height measured by atomic force microscopy (AFM) over the MCF7 parental cells and stably transduced MCF7-PDLIM2 cells after TGF 1 treatment (TGF $\beta 1+)$ in comparison with control untreated cells (TGF $31-)$. Scale bar inside the image is equal to $20 \mu \mathrm{m}$. Figures are representative of 11 AFM measurements (biological replicates) per group, see Additional file 16: Dataset S1 for all measurements (also applies to Fig. 1D). (D) Distribution of Young's modulus measured by AFM over the MCF7 parental cells and stably transduced MCF7PDLIM2 cells after TGF $\beta 1$ treatment (TGF $\beta 1+$ ) in comparison with control untreated cells (TGF $\beta 1-$ ). E) Average height and Young's modulus of the cells measured by AFM: MCF7 and MCF7-PDLIM2 cells after TGF $\beta 1$ treatment (TGF $\beta 1+$ ) in comparison with control untreated cells (TGF $\beta 1$-). Statistics for the key Young's modulus comparisons are shown, see Tab. S1 for full statistics. Eleven AFM measurements (biological replicates) per group. F) Histograms show distribution of Young's modulus in MCF7-PDLIM2 and TGF 31 -treated MCF7 cells compared to parental/untreated MCF7 cells. 
A)

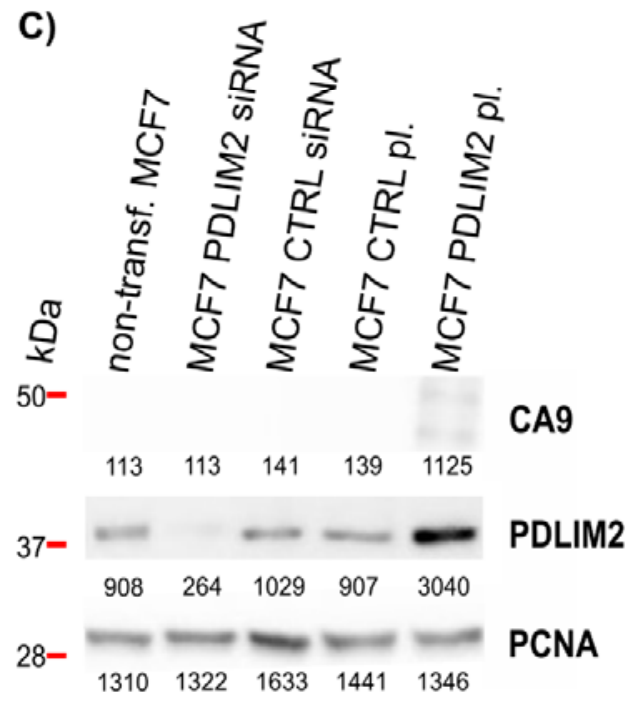

B)

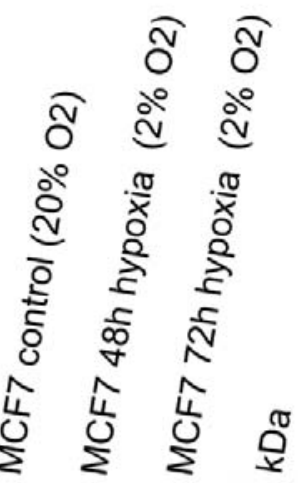

E-cad.

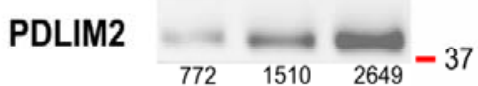

KRT18

ß-catenin

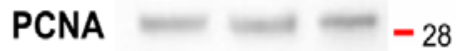

PDLIM2

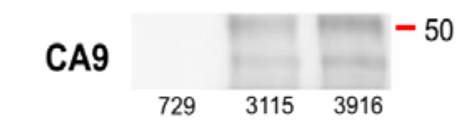

$829 \quad 840 \quad 852$
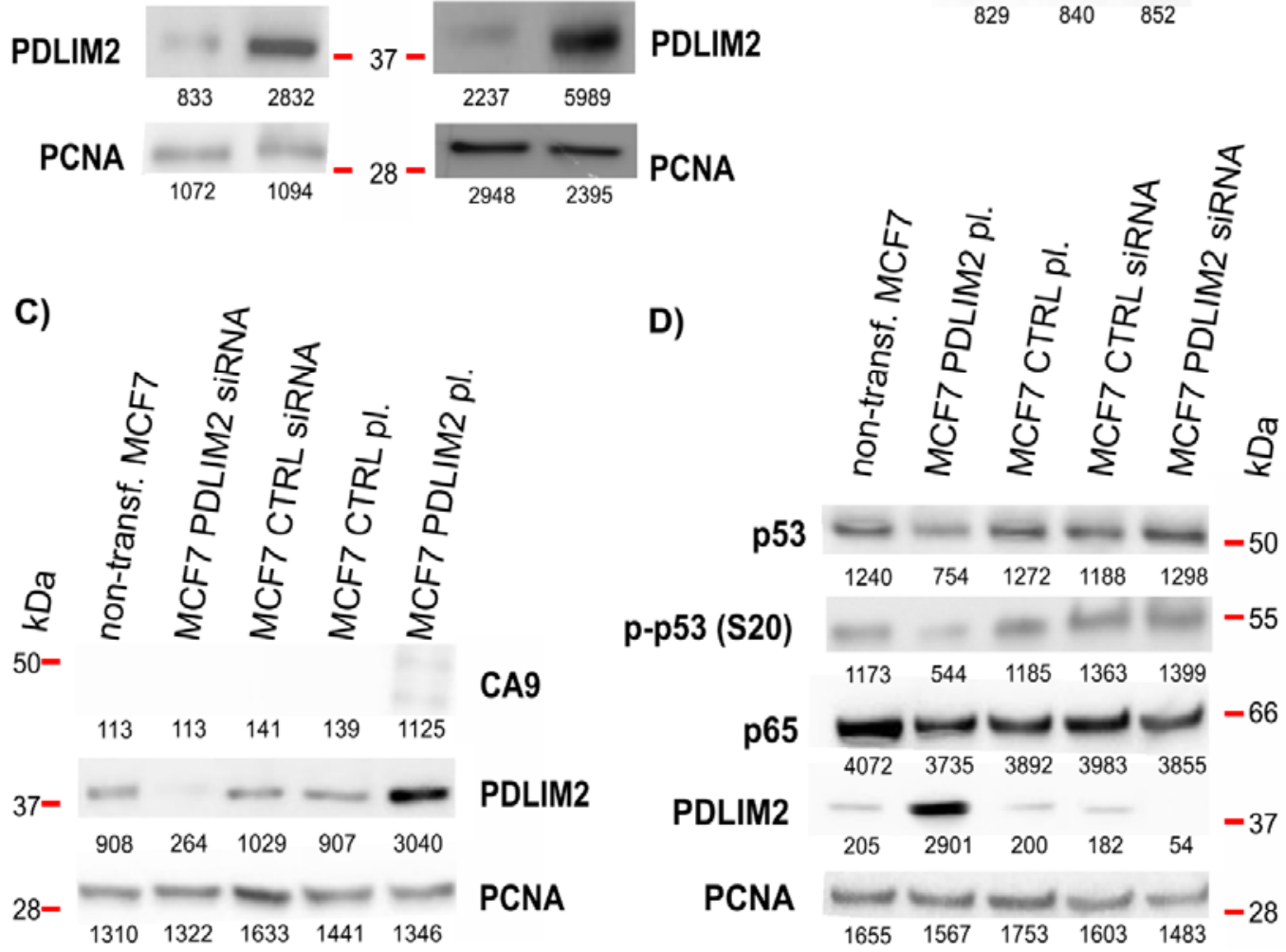

Fig. 2: Effect of EMT on PDLIM2 levels and, conversely, PDLIM2 modulations on selected proteins (MCF7 cells). (A) Effect of EMT induction by TGF 31 treatment ( $1 \mathrm{ng} / \mathrm{ml}$ for 24 hours) and by long-term hypoxia ( $96 \mathrm{~h}$ ) on PDLIM2 protein levels. Successful EMT induction was confirmed by changes in the EMT markers E-cadherin (E-cad.), keratin-18 (KRT18) and $\beta$-catenin. (B) Effect of short-term hypoxia (48 and 72 hours) on PDLIM2 protein levels. Carbonic anhydrase-9 (CA9) was monitored as a control marker of hypoxia induction. (C) Effect of PDLIM2 overexpression on CA9 protein levels. (D) Effect of PDLIM2 protein level modulations on p53 protein levels, p53 (S20) phosphorylation (p-p53 S20), and on p65. Proliferating cell nuclear antigen (PCNA) was used as a 
loading control. Numbers under the protein bands represent their integral optical density $\left(\mathrm{INT}^{*} \mathrm{~mm}^{2}\right)$. Blots are representative of two independent experiments (biological replicates), see Additional files 4 - 7: Figures S4 - S7 for both biological replicates. 
A)

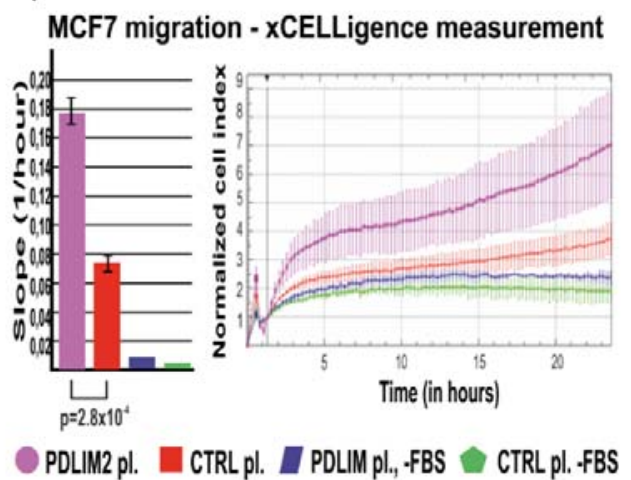

B)

MCF7 invasion - xCELLigence measurement
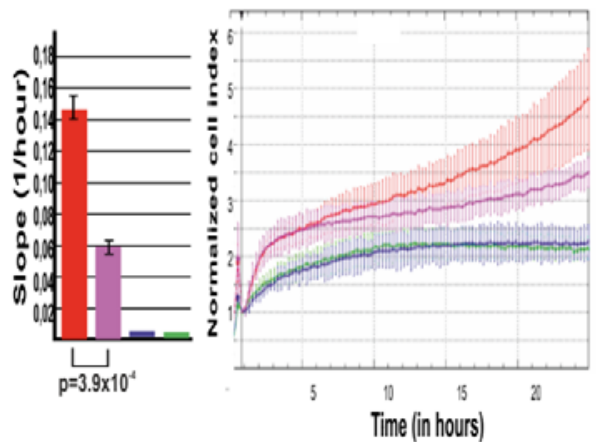

PDLIM2pl. —CTRL pl. $\square$ PDLIM pl., FBS $\triangle$ CTRL pl. FBS
MCF7 migration - Transwell assay

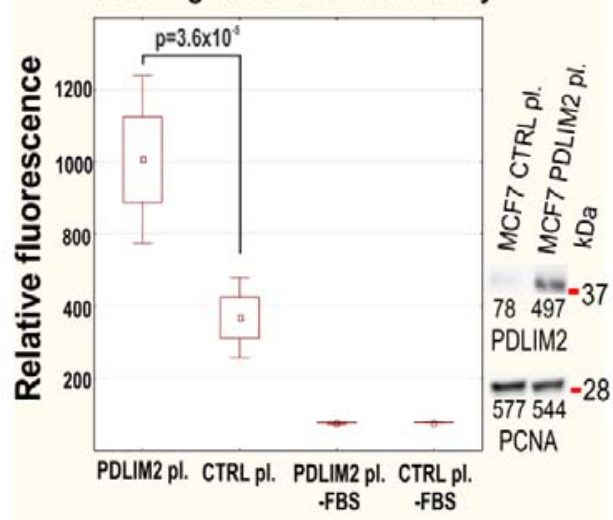

MCF7 invasion - Transwell assay

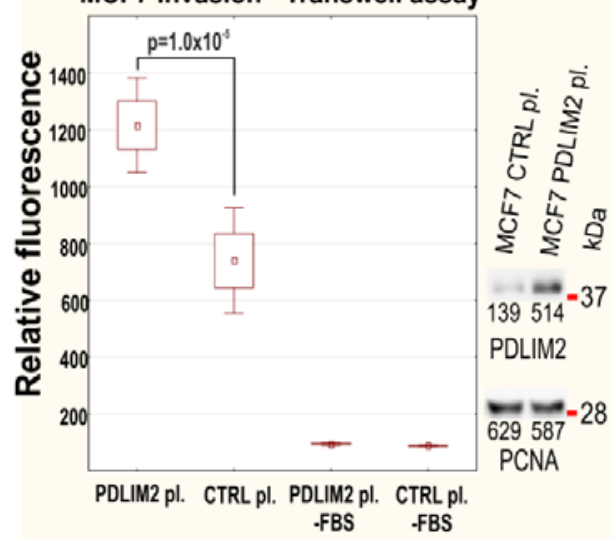

C)

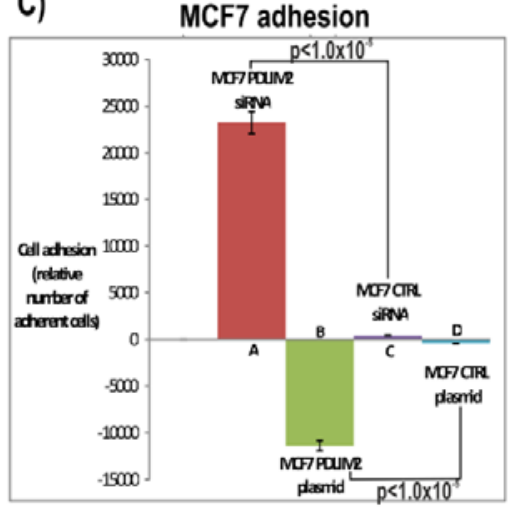

D)

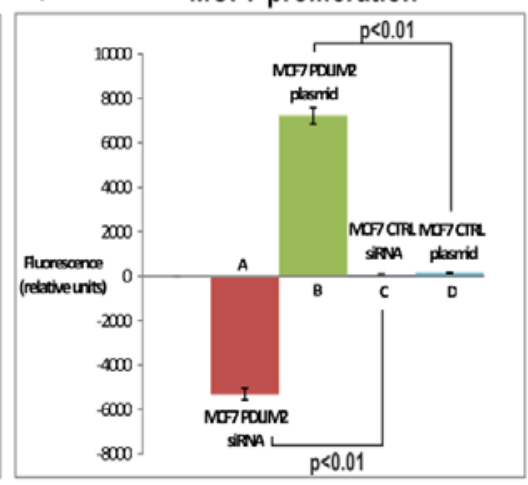

E)

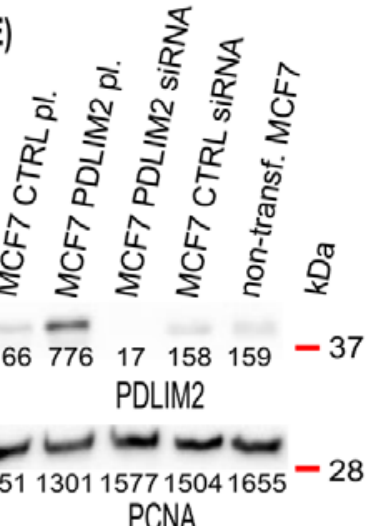

Fig. 3: Effect of PDLIM2 protein level modulations on migration, invasion, adhesion and proliferation of MCF7 cells. (A) Effect of PDLIM2 overexpression (PDLIM2 pl.) on the migration of MCF7 cells (in comparison with control cells with endogenous PDLIM2 levels (CTRL pl.)) measured by the xCELLigence system and Transwell assay. Conditions without fetal bovine serum as the chemoattractant (-FBS) serve as negative controls in A and B. (B) Effect of PDLIM2 overexpression (PDLIM2 pl.) on the invasiveness of MCF7 cells measured by the xCELLigence 
system and by Transwell assay. (C) Effect of PDLIM2 protein level modulations on the adhesion of MCF7 cells. PDLIM2 protein levels were modulated by siRNA suppression (MCF7 PDLIM2 siRNA) compared to the control (MCF7 CTRL siRNA) or by PDLIM2 overexpression (MCF7 PDLIM2 pl.) compared to the control (MCF7 CTRL pl.) (D) Effect of PDLIM2 protein level modulations on the proliferation (viability) of MCF7 cells. (E) Verification of PDLIM2 protein level modulations in MCF7 cells measured in C and D; please see separate verification blots for independently cultivated cells in A and B figure sections/measurements. PCNA was used as a loading control. Numbers under the protein bands represent their integral optical density $\left(\mathrm{INT}^{*} \mathrm{~mm}^{2}\right)$. All data were obtained from at least two independent experiments (see Additional files 17 - 18: Datasets S2 - S3 for migration and invasion experiments). For the detailed design of the xCELLigence and Transwell assay plates see Additional file 1: Figure S1.

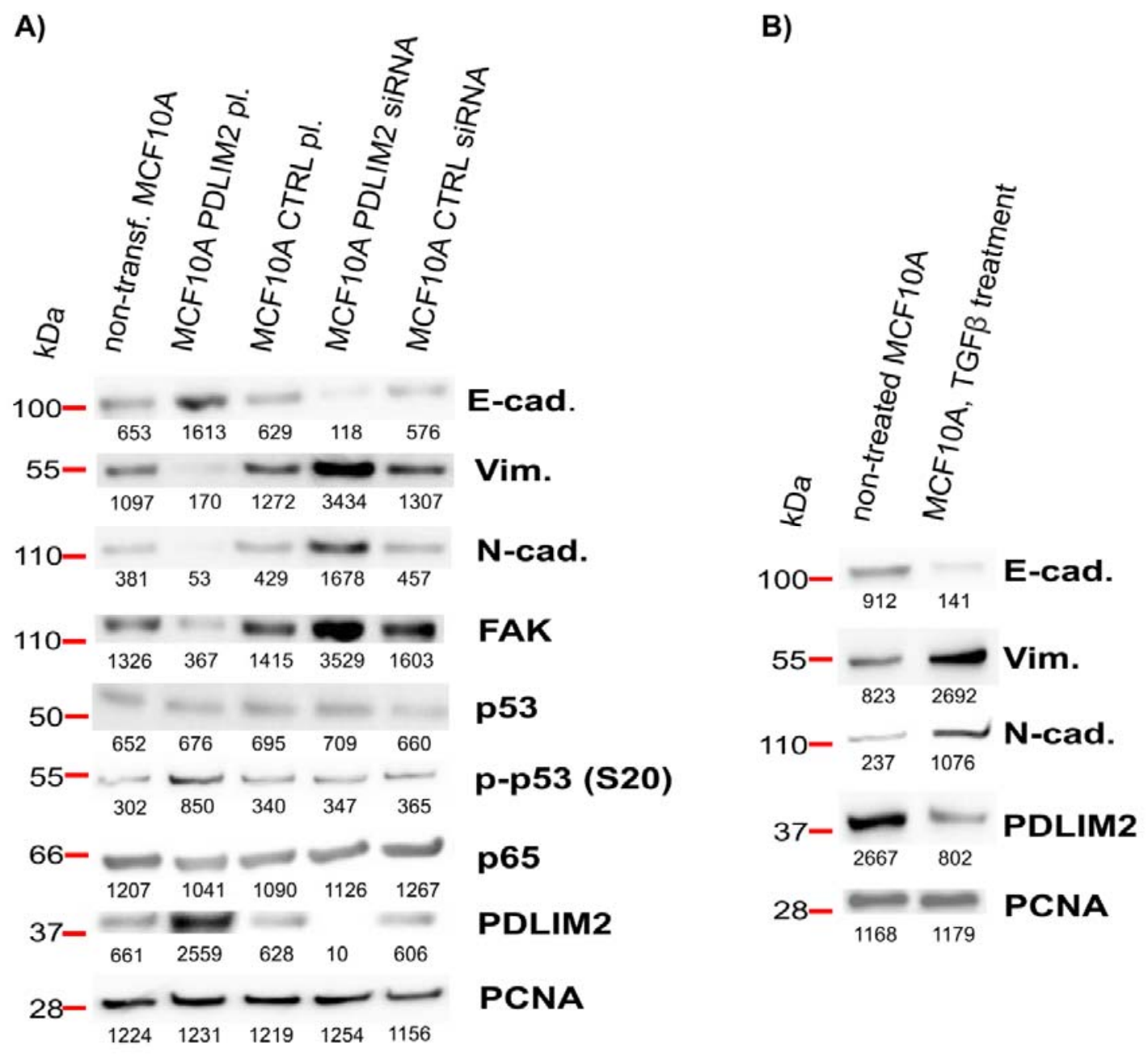

Fig. 4: Effects of PDLIM2 modulations on EMT, and vice versa (MCF10A cells). (A) Effects of PDLIM2 protein level modulations on the EMT markers E-cadherin (E-cad.), N-cadherin (N-cad.) and vimentin (Vim.) as well as FAK levels, p53, p53 (S20) phosphorylation and p65. (B) Effects of EMT induction by treatment with TGF $\beta 1(1 \mathrm{ng} / \mathrm{ml}$ for 24 hours) on PDLIM2 protein levels and EMT markers. Numbers under the protein bands represent their integral optical density $\left(\mathrm{INT} * \mathrm{~mm}^{2}\right.$ ). Blots are representative of two independent experiments (biological replicates), see Additional files 8 - 9: Figures S8 - S9 for both biological replicates. 
A)

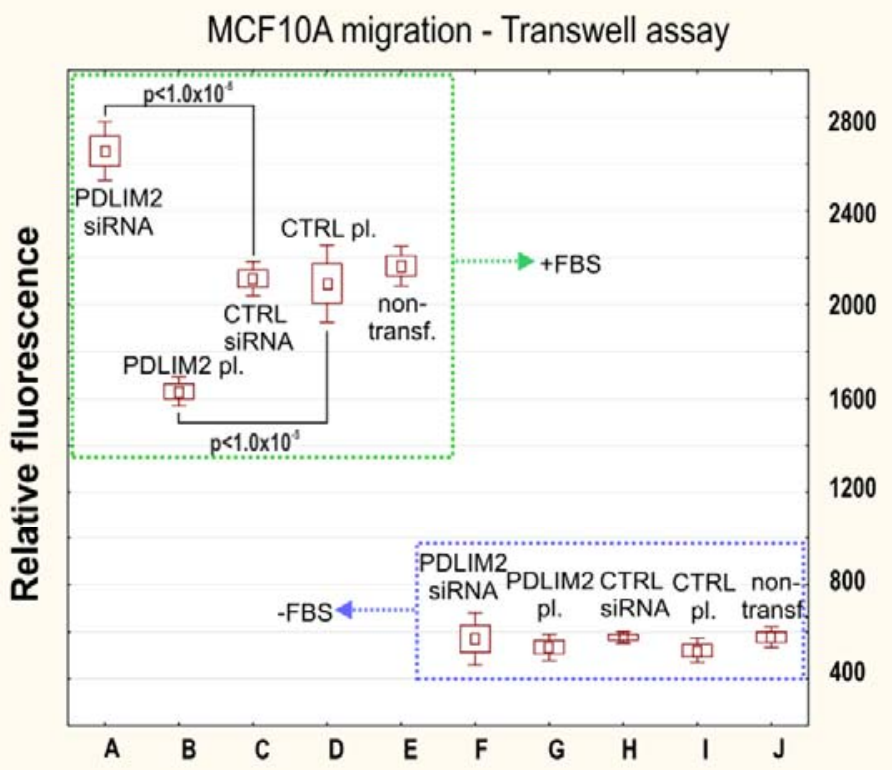

B)

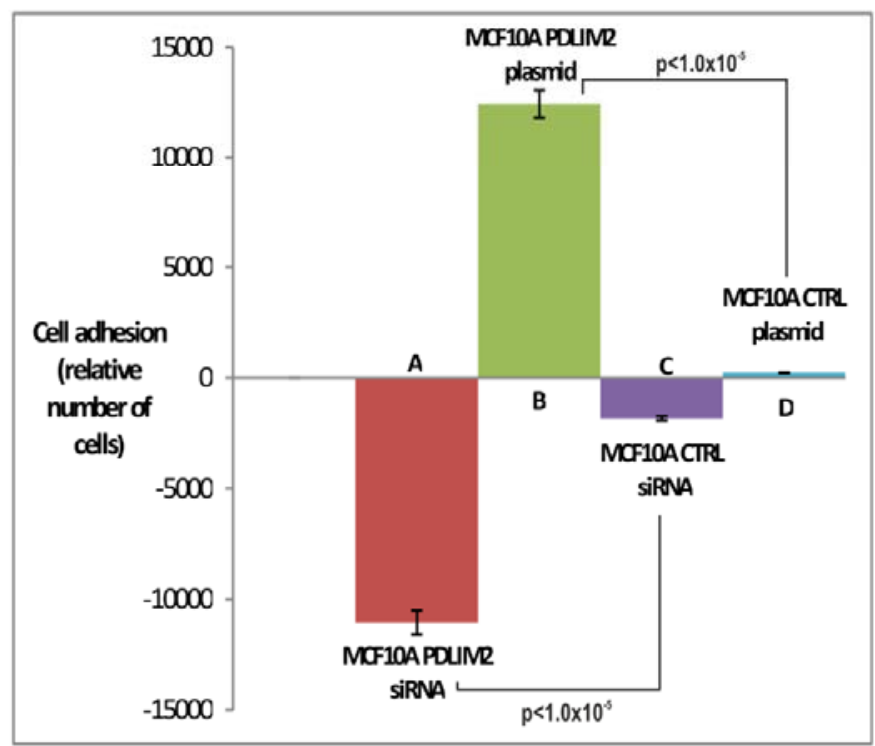

C)

800

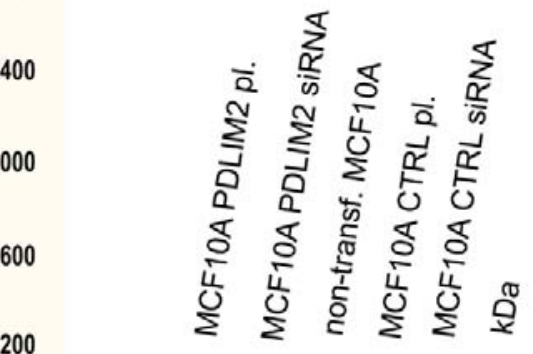

PDLIM2 $\underset{1140}{128} \underset{356}{-}-\frac{-37}{366}-\frac{}{393}$

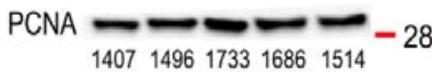

D)

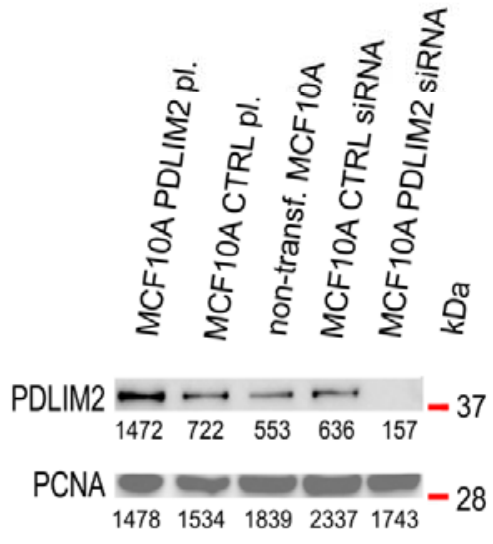

Fig. 5: Effect of PDLIM2 protein level modulations on the migration and adhesion of MCF10A cells. (A) Effects of PDLIM2 protein level modulations on MCF10A cell migration. PDLIM2 protein levels were modulated by siRNA suppression (PDLIM2 siRNA) compared to the control (CTRL siRNA) or by PDLIM2 overexpression (PDLIM2 pl.) compared to the control (CTRL pl.) Conditions without fetal bovine serum as a chemoattractant (-FBS) serve as negative controls in A. (B) Effects of PDLIM2 protein levels on the adhesion of MCF10A cells. See legend to A for explanation. (C) and (D) Verification of PDLIM2 protein level modulations in MCF10A cells for A and B measurements, respectively. PCNA was used as a loading control. Numbers under the protein bands represent their integral optical density $\left(\mathrm{INT}^{*} \mathrm{~mm}^{2}\right)$. All data were obtained from at least two independent experiments (see Additional file 19: Dataset S4 for migration experiments). 


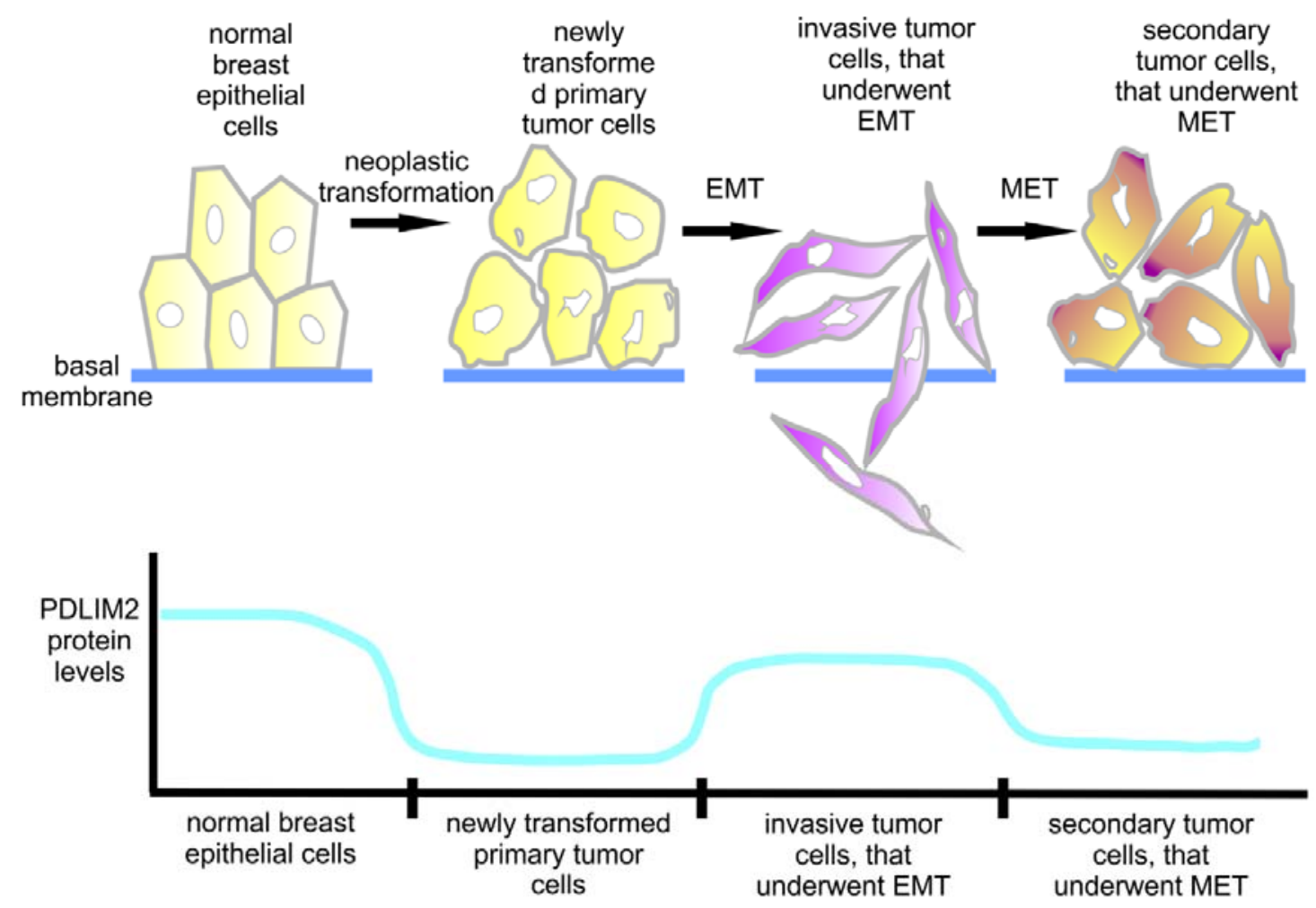

Fig. 6: Model of context-dependent changes in PDLIM2 protein levels during breast oncogenesis based on the data presented here. High PDLIM2 protein levels in normal epithelial breast cells are decreased during neoplastic transformation and are kept low in newly transformed tumor cells. However, PDLIM2 levels increase after EMT and are kept high in invasive tumor cells. Finally, PDLIM2 levels go down in secondary tumor cells that undergo MET and are kept as low as in newly transformed tumor cells. 